\title{
Serum Cotinine, Serum F2-isoprostane and Risk of Metabolic Syndrome in Adult Male Tobacco Users
}

\author{
Haymar Soe Win, Win Yu Aung, Ohn Mar
}

\section{ABSTRACT}

Data on risk of metabolic syndrome among various forms of tobacco consumption in Myanmar tobacco users are currently limited. The present study aimed to determine and compare nicotine metabolites serum cotinine, oxidative stress marker serum F2-isoprostane in adult male tobacco users, and to find out relationships between these parameters and risk of metabolic syndrome. This cross-sectional study was done in 30 to 45 years old males: 84 cigarette smokers, 84 cheroot smokers and 84 betel quid with tobacco chewers. Metabolic syndrome was defined by National Cholesterol Education Program Adult Treatment Panel III definition. Serum cotinine concentration of cigarette smokers was significantly higher than that of cheroot smokers $(p=0.026)$, however, no significant difference was seen between cigarette smokers and betel quid with tobacco chewers ( $p=1.000)$, and between cheroot smokers and betel quid with tobacco chewers $(p=0.248)$. Serum $F 2$-isoprostane concentration was significantly higher $(p=0.001)$ in cigarette smokers than cheroot smokers and betel quid with tobacco chewers, but no significant difference was observed between cheroot smokers and betel quid with tobacco chewers $(p=1.000)$. Compared with betel quid with tobacco chewers, cigarette smokers had 5.2 times $(95 \%$ CI, 2.3-11.4) $(p<0.001)$ and cheroot smokers had 1.4 times $(95 \%$ CI, 0.623.3) $(\mathrm{p}=\mathbf{0 . 4 0 2}$ ) higher risk of having metabolic syndrome. There was a significant association between the presence of metabolic syndrome and high serum cotinine as well as high serum F2-isoprostane. A significant correlation between serum cotinine and serum $F 2$-isoprostane was found in betel quid with tobacco chewers, but not in cigarette smokers and cheroot smokers. The present study showed that both nicotine and oxidative stress take part in the pathogenesis of metabolic syndrome. Cigarette smoking has the highest risk of having metabolic syndrome, however, cheroot smoking as well as betel quid with tobacco chewing is related to metabolic syndrome as well.

Keywords: Cotinine, F2-isoprostane, Metabolic syndrome, Tobacco.

Published Online: January 15, 2021.

ISSN: 2593-8339

DOI: $10.24018 /$ ejmed.2021.3.1.604

Haymar Soe Win*

University of Medicine 1, Yangon, Myanmar.

(e-mail: haymarsoewin198@gmail.com)

Win Yu Aung

University of Medicine 1, Yangon, Myanmar.

(e-mail: wyuaung@gmail.com)

Ohn Mar

University of Medicine 1, Yangon,

Myanmar.

(e-mail: dr.ohnma@gmail.com)

*Corresponding Author

\section{INTRODUCTION}

Tobacco is regarded as the most addictive substance in the world [1]. About $79.8 \%$ of Myanmar males are tobacco users [2]. This is the highest percentage among South-East Asia countries [3]. There are two main forms of tobacco use: smoking and smokeless tobacco use. Cigarette smoking is the most common form of smoked tobacco use but some people prefer cheroot, a kind of smoked tobacco made traditionally by hands. Among various forms of smokeless tobacco use in Myanmar, betel quid chewing is the most popular one, and is very common in people who want to give up smoking.

Multiple biomarkers of tobacco exposure have been reported among which cotinine appears to be the most specific and sensitive biomarker [4]. Cotinine, the major metabolite of nicotine, is formed in the liver by the cytochrome P450 2A6 enzyme [5]. In comparing serum cotinine levels between smokers and betel quid with tobacco chewers, the results are still controversial [6], [7]. It has been noted that composition of betel quid varies from country to country. In fact, Myanmar betel quid contains tobacco according to individual preference. Moreover, Myanmar cheroot is prepared by adding varying amounts of tobacco. Yet, there is no data regarding cotinine level in cheroot smokers and betel quid with tobacco chewers in Myanmar.

Metabolic syndrome includes the constellation of various metabolic abnormalities including obesity, hyperglycemia, dyslipidemia and elevated blood pressure. It has been reported that smoking [8] and betel quid chewing [9] are associated with risk of metabolic syndrome. In Myanmar, only a few studies reported derangement of some of metabolic markers in smokers, and only one study had determined the risk of metabolic syndrome in betel quid chewers. Thus, there is limited evidence regarding risk of metabolic syndrome in Myanmar tobacco users. Moreover, though tobacco use has been proven to have risk of metabolic syndrome, mechanisms leading to occurrence and 
progression of the disease are multiple and still under investigation.

Oxidative stress plays an important role in development of metabolic syndrome [10]. Evidence suggests that smoking can cause oxidative modification in vivo [11], [12]. Tobacco contains not only nicotine as a pro-oxidant [13] but also many other pro-oxidants compounds such as phenolic compounds [14], nitrate and metals [15]. It was suggested that potential mechanism of increased oxidative stress associated with smoking is either due to nicotine [13] or the direct actions of various pro-oxidants present in tobacco [16].

F2-isoprostane which is an isomer of prostaglandin F2 $\alpha$ (PGF2 $\alpha$ ), has been regarded as the most reliable marker for assessing oxidative stress [17], [18]. Although increased level of F2-isoprostane in smokers has been reported by some studies [11], [12], the relationship between serum cotinine and F2-isoprostane was still contentious in smokers [19], [20]. Thus, the relationship between nicotine and F2isoprostane in smokers is needed to be elaborated.

Therefore, the present study aimed to determine and compare serum cotinine, serum F2-isoprostane levels and the risk of metabolic syndrome among cigarette smokers (CS), cheroot smokers $(\mathrm{CH})$ and betel quid with tobacco chewers (BQTC), and to explore the role of nicotine and oxidative stress in pathogenesis of metabolic syndrome in tobacco users by determining the association between serum cotinine, serum F2-isoprostane and risk of metabolic syndrome. It is hoped that information on risk of metabolic syndrome in different tobacco users can be useful in raising public awareness of deleterious effects and danger of tobacco use.

\section{PROCEDURE}

This study was done after the approval of the Research and Ethics Committee of University of Medicine 1, Yangon (Approved number - 115/UM1, REC.2017). A total of 252 adult male tobacco users residing in Yangon, age between 30-45 years, participated in the present study; cigarette smokers $(\mathrm{CS})(\mathrm{n}=84)$, cheroot smokers $(\mathrm{CH})(\mathrm{n}=84)$, betel quid with tobacco chewers (BQTC) $(n=84)$. Current cigarette smokers who smoke at least 7 cigarettes per day for a year without betel quid chewing and cheroot smoking were regarded as CS, current cheroot smokers who smoke at least 5 cheroots per day for a year without betel quid chewing and cigarette smoking as $\mathrm{CH}$, and current betel quid with tobacco chewers who chew at least 10 betel quids per day for a year without smoking as BQTC.

Written informed consent was taken. Body weight and standing height were measured by weight-height scale. Waist circumference was measured by measuring tape. Blood pressure was measured by auscultatory method with mercury sphygmomanometer after 15 minute-sitting rest.

The subjects were requested to avoid smoking or betel quid chewing the whole morning before blood sample collection. After 8-hour overnight fasting, about $5 \mathrm{~mL}$ was withdrawn. Within two hours of sample collection, the samples were transported in ice box $\left(+2{ }^{\circ} \mathrm{C}\right.$ to $\left.+8{ }^{\circ} \mathrm{C}\right)$ to Postgraduate Research Laboratory, Department of Physiology, University of Medicine 1, Yangon. The plasma glucose was determined by Glucose oxidase, phenol, 4aminophenazone method on the day of blood collection. After centrifugation of blood samples, serum samples were kept in four separate screw-tight bottles and stored at $-20^{\circ} \mathrm{C}$ until analysis for determination of cotinine, F2-isoprostane, triglyceride and high-density lipoprotein cholesterol (HDLc). Cotinine and F2-isoprostane were determined by ELISA kits (Cloud-Clone, USA). Serum triglycerides level was determined by glycerol phosphate oxidase/phenol aminophenazone method. Serum HDLc level was determined by precipitation method.

According to the criteria of National Cholesterol Education Program Adult Treatment Panel III [21], metabolic syndrome is diagnosed if three of the following metabolic markers are fulfilled, i.e., elevated waist circumference $(>90 \mathrm{~cm}$ in men), increased fasting plasma glucose ( $\geq 110 \mathrm{mg} / \mathrm{dL}$ ), elevated blood pressure (if systolic blood pressure $>135 \mathrm{mmHg}$ and diastolic blood pressure $>85 \mathrm{~mm} \mathrm{Hg})$, raised triglyceride level $(\geq 150 \mathrm{mg} / \mathrm{dL})$, low high-density lipoprotein cholesterol ( $<40 \mathrm{mg} / \mathrm{dL}$ in men).

Data was analyzed by using the Statistical Package for Social Science (SPSS) software version 22. Numerical variables were expressed as mean $\pm \mathrm{SD}$. One way ANOVA was used for comparison of serum cotinine concentrations among three groups and post-hoc analysis was done by Bonferroni test. For comparison of serum F2-isoprostane concentrations, Kruskal Wallis test was used. The p value $<0.05$ was considered statistically significant. For determination of risk of metabolic syndrome, crude odds ratio was analyzed by simple logistic regression and adjusted odds ratio was done by multiple logistic regression. The results were expressed as times increasing in odds of having metabolic syndrome. For determination of association between serum levels of cotinine, F2-isoprostane and risk of metabolic syndrome, Chi-square was used.

\section{RESUlts}

General characteristics are relatively comparable among the study groups (Table I). Serum cotinine concentrations of $\mathrm{CS}, \mathrm{CH}$ and BQTC were $1494.66 \pm 632.51,1262.68 \pm 460.21$ and $1415.63 \pm 599.61 \mathrm{pg} / \mathrm{mL}$ respectively. Serum cotinine concentration of $\mathrm{CS}$ was significantly higher than that of $\mathrm{CH}$ $(\mathrm{p}=0.026)$. However, no significant difference was seen between CS and BQTC ( $\mathrm{p}=1.000)$, as well as between $\mathrm{CH}$ and BQTC ( $\mathrm{p}=0.248)$ (Fig. 1).

Serum F2-isoprostane concentrations (median, IQR) of CS, CH and BQTC were 168.26 (116.85-847.54), 109.92 (26.97-291.68) and $91.82 \quad(59.22-179.82) \quad \mathrm{pg} / \mathrm{mL}$ respectively. Serum F2-isoprostane concentration was significantly higher $(\mathrm{p}=0.001)$ in $\mathrm{CS}$ than $\mathrm{CH}$ and BQTC, but no significant difference was observed between $\mathrm{CH}$ and BQTC (p=1.000) (Fig. 2).

Prevalence of metabolic syndrome were $50 \%$ in CS, $25 \%$ in $\mathrm{CH}$ and $14.3 \%$ in BQTC. Risk of metabolic syndrome among the study groups is shown in table II. Relationship between risk of metabolic syndrome and serum cotinine as well as serum F2-isoprostane in tobacco users was shown in table III. No significant correlation was seen between serum cotinine and serum $\mathrm{F} 2$-isoprostane concentrations in tobacco users $(\mathrm{r}=0.12, \mathrm{p}=0.07, \mathrm{n}=252)$. There was also no correlation 
between serum cotinine and serum F2-isoprostane concentrations in CS $(\mathrm{r}=-0.08, \mathrm{p}=0.46, \mathrm{n}=84)$, and in $\mathrm{CH}$ $(\mathrm{r}=0.17, \mathrm{p}=0.11, \mathrm{n}=84)$. However, a significant moderately strong positive correlation was seen in BQTC $(r=0.58$, $\mathrm{p}<0.001, \mathrm{n}=84)$.

TABLE I: THE ARRANGEMENT OF CHANNELS

TABLE I. GENERAL CHARACTERISTICS OF THE STUDY GROUPS

\begin{tabular}{cccc}
\hline $\begin{array}{c}\text { General } \\
\text { characteristics }\end{array}$ & $\begin{array}{c}\mathrm{CS} \\
(\mathrm{n}=84)\end{array}$ & $\begin{array}{c}\mathrm{CH} \\
(\mathrm{n}=84)\end{array}$ & $\begin{array}{c}\text { BQTC } \\
(\mathrm{n}=84)\end{array}$ \\
\hline Age (years) & $36.6 \pm 5.3$ & $38.2 \pm 5^{\dagger}$ & $36.2 \pm 4.6$ \\
Height (m) & $1.66 \pm 0.07^{*}$ & $1.64 \pm 0.06$ & $1.62 \pm 0.07$ \\
Weight $(\mathrm{kg})$ & $65.29 \pm 9.39^{*}$ & $61.13 \pm 10.02$ & $59.03 \pm 8.87$ \\
& ${ }^{*}$ & & \\
BMI (kg/m $\left.{ }^{2}\right)$ & $23.72 \pm 3.06^{*}$ & $22.82 \pm 3.63$ & $22.37 \pm 3.19$ \\
Resting SBP & $133.21 \pm 10.6$ & $134.95 \pm 10.4$ & $129.05 \pm 11.41$ \\
$(\mathrm{mmHg})$ & $9^{*}$ & $99^{\dagger}$ & \\
Resting DBP & $94.69 \pm 8.52$ & $95.5 \pm 9.81$ & $93.43 \pm 11.92$ \\
$(\mathrm{mmHg})$ & & & \\
\hline
\end{tabular}

Data are presented as mean \pm SD.

One-way ANOVA and post hoc Bonferroni test.

* indicates significant difference between CS and BQTC $(\mathrm{p}<0.05)$.

$\dagger$ indicates significant difference between $\mathrm{CH}$ and BQTC $(\mathrm{p}<0.05)$.

$\$$ indicates significant difference between CS and $\mathrm{CH}(\mathrm{p}<0.05)$.

TABLE II. RISK OF METABOLIC SYNDROME AMONG THE STUDY GROUPS

\begin{tabular}{|c|c|c|c|c|}
\hline Tobacco users & $\begin{array}{c}\mathrm{OR}^{\mathrm{a}}(95 \% \\
\mathrm{CI})\end{array}$ & $\mathrm{p}$ value & $\begin{array}{c}\mathrm{OR}^{\mathrm{b}}(95 \% \\
\mathrm{CI})\end{array}$ & $\mathrm{p}$ value \\
\hline BQTC (ref) & 1 & & 1 & \\
\hline $\mathrm{CS}$ & $6(2.9-12.7)$ & $<0.001$ & $\begin{array}{c}5.2(2.3- \\
11.4)\end{array}$ & $<0.001$ \\
\hline $\mathrm{CH}$ & $2(0.9-4.4)$ & 0.084 & $1.4(0.6-3.3)$ & $<0.402$ \\
\hline
\end{tabular}

a Simple logistic regression.

${ }^{\mathbf{b}}$ Multiple logistic regression adjusted for age, BMI and physical activity.

TABLE III. RELATIONSHIP BETWEEN SERUM COTININE, SERUM F2ISOPROSTANE AND METABOLIC SYNDROME IN TOBACCO USERS

\begin{tabular}{lccccc}
\hline $\begin{array}{l}\text { Tobacco users } \\
(\mathrm{n}=252)\end{array}$ & $\begin{array}{c}\text { Metabolic } \\
\text { syndrome } \\
(+)\end{array}$ & $\begin{array}{c}\text { Metabolic } \\
\text { syndrome (-) }\end{array}$ & Total & $\chi^{2}$ & p value \\
\hline $\begin{array}{l}\text { Low serum } \\
\text { cotinine }\end{array}$ & 0 & $46(100 \%)$ & 46 & 23.84 & $<0.001$ \\
$\begin{array}{l}\text { High serum } \\
\text { cotinine }\end{array}$ & $75(36.4 \%)$ & $131(63.6 \%)$ & 206 & & \\
$\begin{array}{l}\text { Low serum } \\
\text { F2-isoprostane }\end{array}$ & $0(0 \%)$ & $63(100 \%)$ & 63 & 35.59 & $<0.001$ \\
$\begin{array}{l}\text { High serum } \\
\text { F2-isoprostane }\end{array}$ & & $114(60.3 \%)$ & 189 & & \\
\hline
\end{tabular}

Pearson Chi-square test.

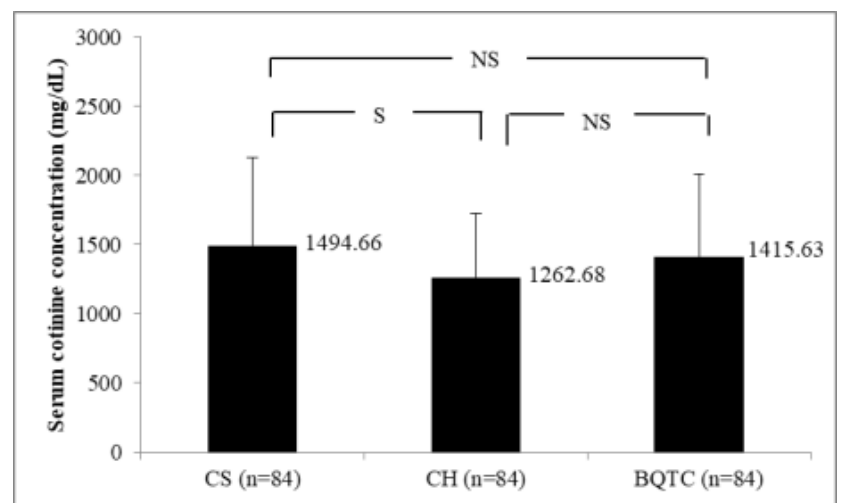

Fig. 1. Fasting serum cotinine concentrations among CS, CH and BQTC. NS = Non-significant $(p>0.05), S=$ Significant $(p<0.05)$. One-way ANOVA and post hoc Bonferroni test.

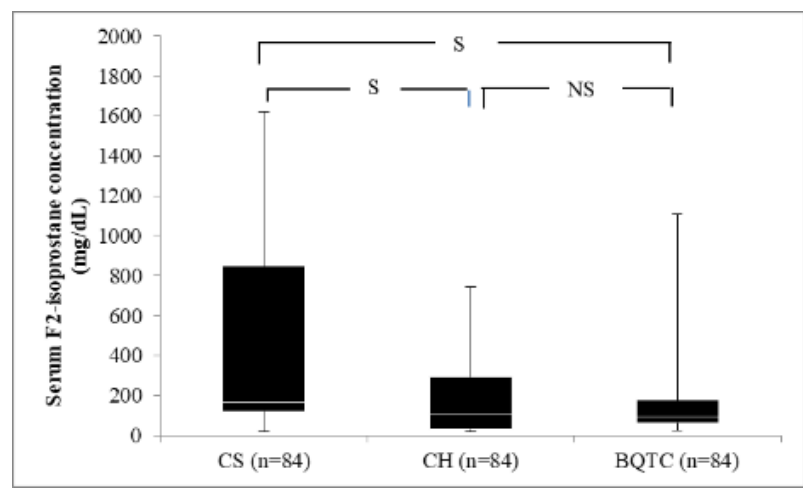

Fig. 2. Fasting serum F2-isoprostane concentrations among $\mathrm{CS}, \mathrm{CH}$ and BQTC.

NS $=$ Non-significant $(p>0.05), S=$ Significant $(p<0.001)$ Kruskal Wallis test.

\section{DISCUSSION}

Cotinine measurement from human body fluids can provide an assessment of exposure to tobacco [22]. Cotinine concentration $1000 \mathrm{pg} / \mathrm{mL}$ in serum [23] and in saliva [24] is used as a cut-off value for the status of tobacco exposure; high tobacco exposure vs low tobacco exposure. In the present study, 84 out of $84(100 \%)$ of CS, 59 out of 84 $(70.2 \%)$ of $\mathrm{CH}$, and 63 out of $84(75 \%)$ of BQTC had serum cotinine concentration above this cut-off value, indicating that majority of the subjects from three study groups had high nicotine exposure. In addition, a significant positive correlation between serum cotinine concentration and daily amount of consumption $(\mathrm{r}=0.282, \mathrm{p}<0.001, \mathrm{n}=252)$ was seen, suggesting that like cigarette smoking, cheroot smoking as well as betel quid with tobacco chewing might cause high tobacco exposure if daily amount of consumption is high.

Mean serum cotinine concentration of non-tobacco-users $(\mathrm{n}=19)$ was also determined and was $729.39 \pm 302.08 \mathrm{pg} / \mathrm{mL}$. Therefore, all three study groups (i.e., tobacco users) had significantly higher serum cotinine levels than the nontobacco-users, regardless of the type of tobacco usage.

There was a significant difference in serum cotinine concentrations among the three study groups with the highest level in the CS group. Nicotine contents of cigarettes, cheroots and betel quids were not determined in the present study. However, Thein, et al. [25] reported that a cigarette contains $24.5 \pm 0.05 \mathrm{mg}$ nicotine and a cheroot contains $14.3 \pm 0.02 \mathrm{mg}$ nicotine. A relatively low nicotine contents was detected in betel quids $(0.6-1.6 \mathrm{mg} / \mathrm{g}$ wet weight of the quid) [26]. Thus, it could be assumed that difference in serum cotinine concentrations between the study groups might be due to difference in nicotine contents in cigarettes, cheroots and betel quids. The highest serum cotinine level in CS might be due to high nicotine contents of cigarettes although there were variations among individual brands.

In the present study, mean serum cotinine concentration of BQTC was higher than that of $\mathrm{CH}$ and was as high as CS. Chewed tobacco augments nicotine absorption through oral mucosa [27] and alkalinizing agents (e.g., lime) and catechu bark added to the quid could enhance the release of nicotine when mixed with tobacco leaves [7]. 
Concerning serum cotinine concentration between CS and $\mathrm{CH}$ of the present study, mean serum cotinine concentration of CS was significantly higher than that of $\mathrm{CH}$. Moreover, daily consumption number for $\mathrm{CH}$ was $\geq 5$ cheroots per day whereas that for CS was $\geq 7$ cigarettes per day in the present study. Higher tobacco exposure in $\mathrm{CS}$ than $\mathrm{CH}$ might be due to higher number of daily consumption and higher content of nicotine in cigarettes [25].

Relatively lower serum cotinine concentration was seen in the present study compared with previous studies [6], [7]. This might be due to differences in the nicotine content of tobacco products, sampling methods, different methods of cotinine measurement, way of smoking and type of cigarette.

Cigarette contains not only nicotine as a source of oxidative stress [13] but also many other varieties of prooxidants [15]. For cheroots, major ingredient is crashed tobacco [28] and for betel quid, major constituents are betel leaves, areca nut, lime and additive tobacco. Both areca nuts [29] and nicotine of tobacco [13] can cause oxidative stress. Therefore, all forms of tobacco consumption can cause increased reactive oxygen species (ROS) formation, resulting in oxidative stress. F2-isoprostane is an eicosanoid of non-enzymatic origin, produced by the random oxidation of phospholipids by oxygen radicals [11]. Blood and urinary F2-isoprostane levels were found to be elevated in oxidative stress [11]. High serum F2-isoprostane concentration is defined as serum F2-isoprostane concentration equal or more than $50 \mathrm{pg} / \mathrm{mL}$ [18]. In the present study, 68 out of 84 $(81 \%)$ of CS had high serum F2-isoprostane concentration. Although $\mathrm{CH}$ and BQTC had significantly lower serum F2isoprostane concentration than CS in the present study, 57 out of $84(67.9 \%)$ of $\mathrm{CH}$ and 64 out of $84(76.2 \%)$ of BQTC had serum F2-isoprostane concentration equal or above $50 \mathrm{pg} / \mathrm{mL}$. Therefore, it was evidenced that oxidative stress occurs in all forms of tobacco consumption, irrespective of the types of tobacco use.

Nicotine directly or indirectly involves in the pathophysiology of metabolic syndrome and its individual components [30], [31]. Arecoline of betel quid also contributes to pathophysiology of metabolic syndrome [32]. Moreover, some investigators reported that oxidative stress is one of the risk factors in the development of metabolic syndrome [19], [33].

In the present study, 42 out of $84(50 \%)$ of CS, 21 out of $84(25 \%)$ of $\mathrm{CH}$ and 12 out of $84(14.3 \%)$ of BQTC had metabolic syndrome according to NCEP/ATP III definition. The percentage of metabolic syndrome in CS in the present study $(50 \%)$ was consistent with that of $57.3 \%$ prevalence rate in a China study [34]. However, it was much higher compared to $27.4 \%$ prevalence of an Oslo study [35] and $20.1 \%$ prevalence of a Japan study [36]. Difference in cutoff value of waist circumference could be the reason of inconsistent prevalence of metabolic syndrome among these studies. The prevalence of metabolic syndrome in the BQTC of the present study (14.3\%) was comparable to $10.1 \%$ prevalence of Taiwan study [37].

It has been documented that elevated serum cotinine and serum F2-isoprostane levels might be reflective of the risk of metabolic syndrome in tobacco users [38], [39]. In the present study, serum cotinine and serum F2-isoprostane levels of the CS were higher than those of $\mathrm{CH}$ and BQTC. Therefore, it is recognizable that CS had the highest nicotine exposure and oxidative stress, and thus risk of metabolic syndrome would be more apparent in them.

According to the results, BQTC had the lowest risk of having metabolic syndrome among the study groups. When BQTC group was regarded as reference, CS had 5.2 times (95\% CI, 2.3-11.4) $(\mathrm{p}<0.001)$ higher risk and $\mathrm{CH}$ had 1.4 times $(95 \% \mathrm{CI}, 0.62-3.3)(\mathrm{p}=0.402)$ higher risk of having metabolic syndrome, after adjusting for age, BMI, and physical activity.

Apparently healthy non-tobacco-users were not included in the present study. However, one previous study from our department determined risk of metabolic syndrome in normal healthy non-tobacco-users and in betel quid chewers, using same methodology and same inclusion criteria as the present study [9]. When age-matched non-tobacco-users of this previous study $(n=22)$ were regarded as reference for the analysis of risk of metabolic syndrome in the study groups of the present study, it was found that CS had 17.1 times (95\% CI, 3.4-86.5) ( $\mathrm{p}<0.005), \mathrm{CH}$ had 4.8 times $(95 \%$ CI, 0.9-24.4) $(\mathrm{p}=0.060)$, and BQTC had 3.3 times $(95 \% \mathrm{CI}$, 0.6-17.8) $\quad(\mathrm{p}=0.163)$ higher risk of having metabolic syndrome than the non-tobacco-users, with adjustment for age, BMI and physical activity. Therefore, the present results revealed that regarding risk of metabolic syndrome, betel quid with tobacco chewing is as much dangerous and harmful as cigarette smoking. Likewise, cheroot smoking is also related to metabolic syndrome and derangement of metabolic parameters.

In the present study, a significant association was observed between high serum cotinine concentration and metabolic syndrome among tobacco users approving that high tobacco exposure can significantly increase the risk of metabolic syndrome, regardless of the route of consumption: smoking or chewing. Moreover, a significant association was noted also between high serum F2-isoprostane and metabolic syndrome in tobacco users. Since F2-isoprostane is regarded as the best available representative of oxidative lipid damage in the body [11], the present finding also confirmed that oxidative stress in tobacco users is related to metabolic syndrome despite of variations in nicotine contents, pro-oxidant contents, types of pro-oxidants and number of daily consumptions among them.

Nicotine produces oxidative stress while metabolizing into cotinine [13] whereas pro-oxidant compounds of tobacco produces oxidative stress while combusting from burning end [15]. In the present study, no significant correlation between serum cotinine and F2-isoprostane was observed among tobacco users; in both $\mathrm{CS}$ and $\mathrm{CH}$. Therefore, it could be implied that F2-isoprostane signifies the oxidative stress caused by other pro-oxidant compounds in tobacco rather than nicotine and nicotine could not be the main contributor of oxidative stress in both $\mathrm{CS}$ and $\mathrm{CH}$.

However, in case of BQTC, nicotine might be the main contributor of oxidative stress. This suggestion is supported by finding of a significant positive correlation between serum cotinine and F2-isoprostane in BQTC of the present study $(\mathrm{r}=0.581, \mathrm{p}<0.001, \mathrm{n}=84)$, indicating nicotine-related oxidative stress. In fact, nicotine [15] as well as areca nuts [33] produces oxidative stress but betel quid with tobacco 
chewers usually add less areca nut whereas as betel quid without tobacco chewers add much areca nuts [9].

\section{CONCLUSION}

In conclusion, serum cotinine and F2-isoprostane levels of the CS were highest among the study groups, and thus risk of having metabolic syndrome was utmost in them. Furthermore, it was found that both nicotine and oxidative stress have a role in the pathophysiology of metabolic syndrome. Some Myanmar people believed that betel quid chewing is less dangerous than cigarette smoking, and therefore use this habit to quit smoking. Moreover, some rural Myanmar people still concern cheroots as a cultural and traditional mark in their ceremonies, considering cheroots are made of natural ingredients and have no potential health hazards. However, the present study indicated that cheroot smoking and betel quid with tobacco chewing also had the risk of having metabolic syndrome, and thus, tobacco is related to metabolic syndrome regardless of the type of consumption.

\section{A. Limitation of study}

One of the limitations of the present study was that apparently healthy non-tobacco-users were not included. So as to conclude the evidence about the risk of metabolic syndrome among the tobacco users, non-tobacco-users group should be involved. Moreover, in order to determine the relationship between the contents and tobacco exposure in different tobacco users, chemical analysis on the constituents of different brands of cigarettes, cheroots and betel quids with tobacco is recommended. Furthermore, individuals with metabolic syndrome have a chance to develop diabetes mellitus and cardiovascular diseases such as myocardial infarction and stroke. In order to study any risk of developing such complications in tobacco users, a longitudinal study is recommended.

\section{B. Conflicts of interest}

The authors declare that they have no competing interests.

\section{ACKNOWLEDGMENT}

We would like to express the great thanks to External Grant Committee, Department of Medical Research, Lower Myanmar for their kind permission to use the grant for our research.

\section{REFERENCES}

1. Gupta PC, Warnakulasuriya S. Global Epidemiology of Areca nut usage. Addiction Biology. 2002; 7: 77-83.

2. World Health Organization. Myanmar Tobacco factsheet 2018 https://apps.who.int/iris/bitstream/handle/10665/272686/, accessed April 8, 2019.

3. World Health Organization. WHO report on the global adult tobacco survey 2018. https://www.who.tobacco/publications/surveillance, accessed April 3, 2019.

4. Jarvis MJ, Primatesta P, Erens B, Feyerabend C, Bryant A. Measuring nicotine intake in population surveys: comparability of saliva cotinine and plasma cotinine estimates. Nicotine \& Tobacco Research. 2003; 5: 349-355.

5. Benowitz NL. Cotinine as a biomarker of environmental tobacco smoke exposure. Epidemiologic Reviews. 1996; 18: 188-204.
6. Honarmand M, Nakhaee A, Moradi M. Comparison of salivary cotinine concentrations in male smokers and smokeless tobacco users. Asian Pacific Journal of Cancer Prevention. 2018; 19 (5): 1363-1366.

7. Singh PN, Natto Z, Saxena R, Bannerjee H, Yel D, Khieng S, et al. Cotinine levels among betel quid users and cigarette smokers in Cambodia. Asia Pacific Journal of Public Health. 2013; 25(5): 84-91.

8. Calo WA, Ortiz AP, Suárez E, Guzmán M, Pérez CM. Association of cigarette smoking and metabolic syndrome in a Puerto Rican adult population. Journal of Immigrant and Minority Health. 2013; 15(4): 810-816.

9. Phyo Ohnmar Swe. Relationship between betel quid chewing and metabolic risk markers. [MMedSc thesis]. Department of Physiology, University of Medicine 1: Yangon; 2018.

10. Hopps E, Noto D, Caimi G, Averna MR. A novel component of the metabolic syndrome: the oxidative stress. Nutrition, Metabolism and Cardiovascular Diseases. 2010; 20: 72-77.

11. Morrow JD, Frei B, Longmire AW, Gaziano JM, Lynch SM, Shyr Y, et al. Increase in circulating products of lipid peroxidation (F2isoprostanes) in smokers-Smoking as a cause of oxidative damage. New England Journal of Medicine. 1995; 332: 1198-1203.

12. Sinzinger H, Kaliman J, Oguogho A. Eicosanoid production and lymphatic responsiveness in human cigarette smokers compared with non-smokers. Lymphology. 2000; 33: 24-31.

13. Ande, A. Cytochrome $P 450$ enzymes and oxidative stress in tobacco/nicotine mediated HIV pathogenesis. [Ph. D Dissertation]. Andhra University: Missouri; 2016.

14. McGrath TE, Chan WG, Hajaligol MR. Low temperature mechanism for the formation of polycyclic aromatic hydrocarbons from the pyrolysis of cellulose. Journal of Analytical and Applied Pyrolysis. 2003; 66: 51-70.

15. Leffingwell JC. Chemical constituents of tobacco leaf and differences among tobacco type. http://preprint.chemweb.com/orgchem/0102001, accessed Oct 3, 2016.

16. Church DF, Pryor WA. Free-radical chemistry of cigarette smoke and its toxicological implications. Environmental Health Perspectives. 1985; 64: 111-126.

17. Milne GL, Musiek ES, Morrow JD. F2-isoprostanes as markers of oxidative stress in Vivo: An Overview. Biomarkers. 2005; 10(1): S10S23.

18. van't Erve TJ, Kadiiskaa MB, London SJ, Masona RP. Classifying oxidative stress by F2-isoprostane levels across human diseases. Redox Biology. 2017; 12: 582-599.

19. Block G, Dietrich M, Norkus EP, Morrow JD, Hudes M, Caan, B, et al Factors associated with oxidative stress in human populations. American Journal of Epidemiology. 2002; 156: 274-285.

20. Black CN, Bot M, Scheffer PG, Penninx BWJH. Sociodemographic and lifestyle determinants of plasma oxidative stress markers 8-OHdG and F2-isoprostanes and associations with metabolic syndrome. Oxidative Medicine and Cellular Longevity. 2016. https://www.hindawi.com/journals/omcl/2016/7530820/, accessed April 23, 2017.

21. National Cholesterol Education Program: Adult Treatment Panel III (NCEP/ATP III). Third report of the National Cholesterol Education Program: Expert panel on detection, evaluation, and treatment of high blood cholesterol in adults. Circulation. 2001; 106: 3143-3421.

22. SRNT Subcommittee of the Society for Research on Nicotine and Tobacco. Biochemical verification of tobacco use and cessation. Nicotine \& Tobacco Research. 2002; 4: 149-159.

23. Benowitz NL, Bernert JT, Caraballo RS, Holiday DB, Wang J. Optimal serum cotinine levels for distinguishing cigarette smokers and nonsmokers within different racial/ethnic groups in the United States between 1999 and 2004. American Journal of Epidemiology. 2009; 169: 236-248.

24. Smith JJ, Robinson RF, Khan BA, Sosnoff CS, Dillard DA. Estimating cotinine associations and a saliva cotinine level to identify active cigarette smoking in Alaska native pregnant women. Maternal and Child Health Journal. 2014; 18: 120-128.

25. Thein KN, Win M, Hlaing TT, Tin N. A study of the effects of tobacco smoking on lipid profile of apparently healthy Myanmar adults. A paper presented at 38th Myanmar Health Research Congress; 2010, Jan; Department of Medical Research (Lower Myanmar), Yangon, Myanmar.

26. Ayo-Yusuf OA, Swart TJP, Pickworth WB. Nicotine delivery capabilities of smokeless tobacco products and implications for control of tobacco dependence in South Africa. Tobacco Control. 2004; 13: 186-189.

27. Behera D, Uppal R, Majumdar S. Urinary levels of nicotine \& cotinine in tobacco users. Indian Journal of Medical Research. 2003; 118: 129133. 
28. Masahiko M. Cheroots in Myanmar, beyond rural development. (2019).

29. Nair UJ, Obe G, Friesen M, Goldberg MT, Bartsch H. Role of lime in the generation of reactive oxygen species from betel-quid ingredients. Environmental Health Perspectives. 1992; 98: 203-205.

30. Pasquali R, Vicennati V. Activity of the hypothalamicpituitary-adrenal axis in different obesity phenotypes. International Journal of Obesity Related Metabolic Disorders. 2000; 24: S47-S49.

31. Andersson K, Arner P. Systemic nicotine stimulates human adipose tissue lipolysis through local cholinergic and catecholaminergic receptors. International Journal of Obesity. 2001; 25: 1225-1232.

32. Calogero AE, Kamilaris TC, Gomez MT, Johnson EO, Tartaglia ME, Gold PW, Chrousos GP. The muscarinic cholinergic agonist arecoline stimulates the rat hypothalamus-pituitary-adrenal axis through a centrally mediated corticotrophin releasing hormone dependent mechanism. Endocrinology. 1989; 125(5): 2445-2453.

33. Baradaran A, Nasri H, Kopael MR. Oxidative stress and hypertension: Possibility of hypertension therapy with antioxidants. Journal of Research in Medical Sciences. 2014; 19(4): 358-367.

34. Zhu YX, Zhang ML, Hou XH, Lu JX, Peng LP, Gu HL, et al. Cigarette smoking increases risk for incident metabolic syndrome in chinese men-Shanghai diabetes study. Biomedical and Environmental Sciences. 2011; 24: 475-482.

35. Holme I, Tonstad S, Sogaard AG, Larsen L, Haheim LL. Leisure time physical activity in middle age predicts the metabolic syndrome in old age: results of a 28 -year follow-up of men in the Oslo study. BMC Public Health. 2007; 7(154): 1-7.

36. Nakanishi N, Takatorige T, Suzuki K. Cigarette smoking and the risk of the metabolic syndrome in middle-aged Japanese male office workers. Industrial Health. 2005; 43: 295-301.

37. Guh JY, Chaung LY, Chen HC. Betel-quid use is associated with the risk of the metabolic syndrome in adults. American Journal of Clinical Nutrition. 2006; 83: 1313-1320.

38. Fujita K, Nishizawa H, Funahashi T, Shimomura I, Shimabukuro M. Systemic oxidative stress is associated with visceral fat accumulation and the metabolic syndrome. Circulation Journal. 2006; 70: 1437-1442.

39. Kim BJ, Han JM, Kang JG, Rhee EJ, Kim BS, Kang JH. Relationship of cotinine-verified and self-reported smoking status with metabolic syndrome in 116,094 Korean adults. Journal of Clinical Lipidology. 2017; 11(3): 638-645.

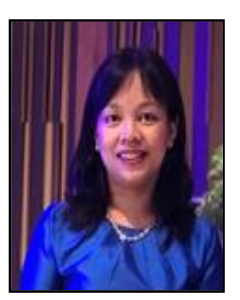

Dr. Haymar Soe Win was born in Mandalay, Myanmar on $18^{\text {th }}$ March 1987. She earned her bachelor of medicine and bachelor of surgery (M.B.,B.S, 2010), master of science in Physiology (M.Med.Sc, 2016) and doctor of Philosophy in Physiology (Ph.D, 2020) from University of Medicine 1, Yangon, Myanmar. She holds great interest in tobacco related health hazards because of the high prevalence of tobacco consumption among Myanmar people. During her initial professional career as a clinician, she worked as an assistant surgeon in Central Women Hospital, Yangon, Myanmar. She then performed as a demonstrator in Department of Physiology, University of Medicine 1, Yangon. Currently, she is working as an Assistant Lecturer in Department of Physiology, University of Medicine 1, Yangon, Myanmar. She is a member of Myanmar Physiology \& Biochemistry Society, and Sakura Science Program. Her publication is:

1. Haymar Soe Win, Thae Nu Htwe, Ohn Mar. Red cell deformability in type 2 diabetic patients with nephropathy. Journal of Clinical Nephrology and Research. 2018; 5(3):1089.

She performed poster presentation in $45^{\text {th }}$ Myanmar Health Research Congress, and oral presentation in $5^{\text {th }}$ NIES International Forum. Her primary research interest was red cell deformability and now she focus on raising public awareness of deleterious effects and danger of tobacco use. Nowadays, Dr. Win holds 8 years of experience in tutoring undergraduate medical students, and continuing her research interest as a routine basis.

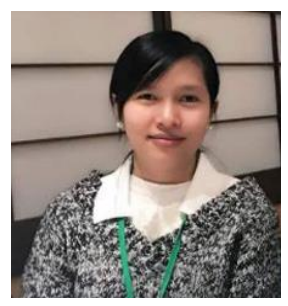

Dr. Win-Yu Aug was born in Yangon in 1978.

Educational background is listed as follow:

$\checkmark 2003-$ M.B., B.S. (University of Medicine 1, Yangon).

$\checkmark$ 2010-M. Med. Sc. (Physiology) (University of Medicine 1, Yangon) on the effect of zinc supplementation on red cell deformability in female thalassemic patients.

$\checkmark$ 2016-Ph.D. (Physiology) (University of Medicine 1, Yangon) on role of serum zinc and Insulin-like growth factor-I in growth velocity and depression in thalassemic adolescents.

She is now serving as a lecturer at Department of Physiology, University of Medicine 1, Yangon. She has supervised many postgraduate students assisting in Research Methodology, Lab investigations and Statistical analysis. In addition, she involves in some Departmental research and collaborative research. Followings are articles with first author:

1. Win-Yu Aung, Thae Nu Htwe, Myat Thandar, Ohn Mar. Prevalence of depression in thalassemic adolescents attending Day Care Center Yangon Children Hospital. Myanmar Medical Journal. 2018; 60(3):22-28.

2. Win-Yu Aung, Mayumi Noguchi, Ei Ei PanNuYi, Zarli Thant, Shigehisa Uchiyama, Tin Tin Win Shwe, Naoki Kunugita, Ohn Mar. Preliminary assessment of outdoor and indoor air quality in Yangon city, Myanmar. Atmospheric Pollution Research. 2019;10 (3);722-730.

3. Win-Yu Aug, Thae Nu Htwe, Myat Thandar, Ohn Mar. Serum zinc status in thalassemic adolescents attending Day Care Centre, Yangon Children Hospital. Iranian Journal of Paediatric Hematology Oncology. Received acceptance and waited for online publication.

Her M. Med. Sc and Ph.D. training focused on trace elements and endocrinology in thalassemic patients. Her now current research works correlate with air pollution and its health effect.

She is now a member of Myanmar Endocrine Society and Myanmar Hypertension Society. She received Best Poster Award in 5th International Forum on Sustainable Future in Asia (5th NIES International Forum), Max Hotel, Yangon, Myanmar, 21st -22nd, January 2020.

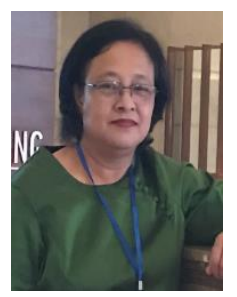

Ohn Mar was born in Yangon, Myanmar, on 8 January 1961. The author's educational background is listed below.

1.M.B., B.S, Institute of Medicine (1), Yangon, Myanmar, 1985.

2.M.Med.Sc. (physiology), University of Medicine (2), Yangon, Myanmar, 1995.

3.Ph D (physiology), University of Medicine (1), Yangon, Myanmar, 2003.

4. Dip. MEd., University of Public Health, Yangon, Myanmar, 2011.

She was a DEMONSTRATOR at the Department of Physiology from Sept 1989 to July 1996; an ASSISTANT LECTURER from July 1996 to June 2003; a LECTURER from June 2003 to May 2007, and an ASSOCIATE PROFESSOR from May 2007 to Oct 2009. She has been a PROFESSOR and HEAD of the Department of Physiology since Oct 2009. Current Job is Professor and Head, Department of Physiology, University of Medicine (1), Yangon, Myanmar. Previous publications are.

1. Win-Yu Aung, Mayumi Noguchi, Ei-Ei Pan-Nu Yi, Zarli Thant, Shigehisa Uchiyama, Tin-Tin Win-Shwe, Naoki Kunugita, Ohn Mar Preliminary assessment of outdoor and indoor air quality in Yangon city, Myanmar. Atmospheric Pollution Research, Volume 10, Issue 3, May 2019, Pages 722-730.

2. Ei Ei Pan Nu Yi, Nay Chi Nway, Win Yu Aung, Zarli Thant, Thet Hnin Wai, Kyu Kyu Hlaing, Cherry Maung, Mayuko Yagishita, Yang Ishigaki, Tin-Tin Win-Shwe, Daisuke Nakajima, and Ohn Mar Preliminary monitoring of concentration of particulate matter (PM2.5) in seven townships of Yangon City, Myanmar. Environmental Health and Preventive Medicine December 2018; 23(1): 53. Published online 2018 Oct 25. doi: 10.1186/s12199-018-0741-0.

3. Nay Chi Nway, Yuji Fujitani, Seishiro Hirano, Ohn Mar, Tin-Tin Win-Shwe Role of TLR4 in olfactory-based spatial learning activity of neonatal mice after developmental exposure to diesel exhaust origin secondary organic aerosol. NeuroToxicology, Volume 63, December 2017, Pages 155-165.

Her previous research interest was on cardiovascular physiology, and autonomic function. Her current research interest is on air quality (both indoor and outdoor) assessment in Yangon, Myanmar.

Prof. Ohn Mar is a vice-president, Physiology and Biochemistry Society, Myanmar Medical Association (2018 - to date), a vice-president, Hypertension Society, Myanmar Medical Association (2019 - to date), and a member of EIM (Exercise is Medicine), Myanmar National Technical Committee (2019 - to date). 